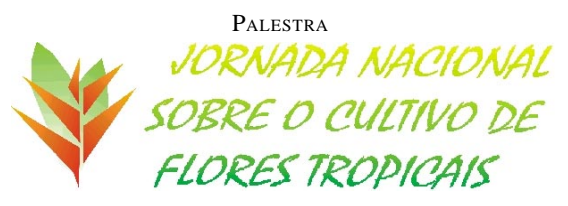

\title{
Diagnóstico da produção de flores tropicais na região do Vale do Ribeira
}

\author{
EDSON SHIGUEAKI NOMURA ${ }^{(1)}$
}

\section{INTRODUÇÃO}

Até meados da década de 50 a floricultura nacional foi inexpressiva economicamente, caracterizada como atividade secundária perante outras atividades agrícolas, utilizando tecnologia incipiente e se concentrando próxima às capitais da região sul e sudeste.

Posteriormente, houve expansão do cultivo de flores e plantas ornamentais para o paisagismo, destinado principalmente a jardins e quintais das residências. Com aumento dos empreendimentos imobiliários, principalmente "shopping center" e conjuntos residenciais, houve relevante aquecimento do setor.

Com a implantação da Cooperativa Agropecuária Holambra, o comércio de plantas ornamentais foi profissionalizado, permitindo o aprimoramento das atividades desenvolvidas pelos produtores em termos de quantidade e qualidade dos produtos, passando a ser atendidos pelo sistema de comercialização moderno e transparente, conhecido como veiling. Esse sistema foi implantado em 1991 e conduziu a floricultura nacional ao seu estádio de desenvolvimento atual.

Atualmente a floricultura é um setor altamente competitivo, que exige a utilização de tecnologias avançadas, profundo conhecimento técnico pelos produtores e um sistema eficiente de distribuição e comercialização.

O gasto com flores no Brasil em 1998 girou em torno de US\$ 6,00 per capita ao ano, ainda baixo se comparado à Noruega, maior consumidor de flores, que gasta cerca de US\$143,00 per capita ao ano. A diferença entre o consumo nacional com outros países desenvolvidos permite inferir que há um imenso potencial no mercado de flores, ainda inexplorado no Brasil.

\section{REGIÕESPRODUTORAS}

Destacam-se, por ordem decrescente de importância de produção, os Estados de São Paulo, Minas Gerais, Rio de Janeiro, Rio Grande do Sul, Santa Catarina, Pernambuco, Paraná e Goiás. Nas demais unidades da federação a horticultura ornamental é pouco desenvolvida, sendo que a maior parte das floríferas disponíveis no mercado são provenientes de outras regiões.

As principais espécies em cultivo podem ser agrupadas em: flores de corte (crisântemo, rosa, gipsofila, gradíolo, cravo, estrelítzia, lírio, margarida, antúrio, gérbera e outras); flores envasadas (violeta africana, prímula, crisântemo, begônia, antúrio, ciclâmen, gloxínia, orquídeas e outras); outras plantas envasadas (cactos, samambaias e aráceas); folhagens (marantáceas, aráceas, acantáceas, pteridófitas); arbustos diversos; forrações diversas e palmeiras diversas.

De acordo com KIYUNA et al. (2002), as principais regiões produtoras, tanto em termos de área cultivada como de valor da produção são: Mogi-Mirim, Bragança Paulista, Mogi das Cruzes, Campinas, Sorocaba, Itapetininga e Registro. A região de Atibaia, por exemplo, concentra $65 \%$ dos produtores do Estado e cerca de $90 \%$ de sua produção é comercializada no Entreposto Terminal de São Paulo (ETSP), da CEAGESP, e no Mercado Permanente da CEASA-Campinas (INFORMATIVO IBRAFLOR, 2001).

A produção de flores e plantas ornamentais na região do Vale do Ribeira teve inicio a partir da década de 60 , principalmente com a produção do antúrio pelos produtores Sojiro Shimizu e Tosuke Sassaki, que o avaliaram como a cultura propícia para o Vale do Ribeira. Começaram a realizar visitas às outras regiões produtoras e adquiriram mudas de antúrio, formando as suas primeiras matrizes. A partir destas, realizou-se cruzamentos entre plantas de interesse e muitas mudas foram distribuídas para produtores por toda a região e, dentre eles, o $\mathrm{Sr}$. Takeshi Oki, agricultor do município de Iguape/SP, atualmente um dos maiores produtores de antúrio no Brasil, com cerca de 5 ha de viveiro.

Atualmente o antúrio constitui a principal espécie de flor tropical cultivada na região, com cerca de 25 ha, distribuídos pelos municípios de Iguape, Pariqueraaçu e Registro. Apesar de haver grande área de produção, falta um programa de padronização das flores para atender as exigências das empresas exportadoras, além de não existir interesse desses produtores em investir no mercado externo. O tradicionalismo arraigado e os altos custos de produção desestimulam os produtores em investir na aquisição de variedades selecionadas e na montagem de viveiros mais adequados para atender os padrões de qualidade para exportação.

Outras espécies cultivadas na região do Vale do Ribeira são as helicônias, alpínia e zingiberáceas, mas com pouca expressão, geralmente produzidas com pouco investimento e comercializadas mudas para a composição de parques e jardins. Apesar disso, vem crescendo o interesse no seu cultivo como flor de corte, devido às suas variações de cores e formas exóticas e ao sucesso da produção na região Nordeste, que atraem cada vez mais o mercado internacional.

\footnotetext{
${ }^{(1)}$ Pesquisador do Pólo Regional de Desenvolvimento Sustentável do Agronegócios do Vale do Ribeira - APTA Regional
} 
Segundo JUNQUEIRA e PEETZ (2007), as flores e folhagens tropicais, provenientes do Brasil, como helicônias, alpínias, bastão do imperador, ananás ornamental, dracenas, cordilines, foram comercializadas na Europa, especialmente na Itália, Alemanha, Holanda e Polônia. Além disso foram exportadas na forma de buquês prontos para a exposição e comercialização direta nos pontos de venda, especialmente na Suíça, Portugal e França, com origem, principalmente, nos estados de Pernambuco, Alagoas e Ceará.

As flores tropicais têm condições de se firmar no mercado mundial, pois as condições naturais (solo e clima) que o Brasil desfruta são importantes armas para o aumento de nossa participação, de modo tranqüilo e seguro. Além desses fatores oferecidos pela natureza, temos a mãode-obra de algumas etnias, que há gerações lidam com flores, e proximidade aos principais centros consumidores.

Na tabela 1 são apresentados os valores de produção de flores, plantas ornamentais e gramas nos Pólos Regionais da APTA. Segundo KIYUNA et al. (2003) o Pólo do Vale do Ribeira apresenta valores de $\mathrm{R}$ \$ 9,92 milhões, chamando muito a atenção, pois esta região se caracteriza por apresentar um dos mais baixos indicadores socioeconômicos, devido à histórica ausência de infraestrutura básica, topografia acidentada e grandes áreas preservadas da Mata Atlântica (92\%). Apesar de reduzida área de exploração agrícola, o setor está em plena expansão, principalmente na produção de árvores, palmeiras nativas e exóticas, antúrios, helicônias, etc. A produção de flores e plantas ornamentais está se tornando uma alternativa real de produção para os produtores, principalmente para os pequenos, fazendo frente aos baixos preços recebidos pela produção do chá e da banana nos últimos anos, que ainda são as principais cadeias produtivas da região (KIYUNA et al., 2003).

Na tabela 2 são apresentados os valores de produção agropecuária e estimativa de produção de flores e plantas ornamentais nos Pólos Regionais da APTA de 2001. Segundo KIYUNA et al. (2003), no Pólo do Vale do a participação do setor é de 2,8\%, quando comparado com as principais atividades da agropecuária paulista. Isso evidenciou a importância da floricultura nos Pólos Regionais de Desenvolvimento do Estado de São Paulo em termos de participação do valor da produção do setor na agropecuária paulista, destacando as regiões: Sede, os Pólos Leste Paulista, Vale do Ribeira, Vale do Paraíba e Sudoeste Paulista, localizados em um raio de $200 \mathrm{~km}$ dos principais mercados. Os resultados sinalizam sobre os rumos que agentes do setor e as políticas governamentais devem tomar para que a floricultura obtenha sucesso. Além disso, dados e indicadores do valor da produção de flores, plantas ornamentais e gramas de cada Pólo de Desenvolvimento Regional, mais próximos da realidade, auxiliam na tomada de decisões e contribuem para a melhoria dos indicadores sócio-econômicos nessas regiões.

Atualmente, devido a diversas crises na cultura do chá e maracujá, aumento nos custos de produção para o controle da Sigatoka Negra e o aumento da competitividade na produção de banana, muitos produtores estão reduzindo suas áreas com o plantio de palmeiras produtoras de palmito (pupunha e real), flores e plantas ornamentais. Devido ao baixo investimento e conhecimento técnico destes novos produtores, estão sendo comercializados produtos de baixa qualidade, sem padronização e sem cadastro pelos órgãos competentes, desencadeando um processo de desvalorização das plantas ornamentais, prejudicando o mercado e diminuindo a renda dos produtores mais tecnificados.

Outro problema é a falta de inovação tecnológica dos produtores de flores e plantas ornamentais, que ainda vendem seus produtos na forma de "torrão", ou seja, produzidos a céu aberto e quando as plantas atingem tamanho para comercialização, elas são arrancadas com um pequeno torrão e envoltas em saco de ráfia para evitar a perda da terra aderida. Isso leva a uma grande exportação de terras férteis, provocando um empobrecimento gradual do solo de suas propriedades.

Tabela 1. Estimativa do valor da produção de flores, plantas ornamentais e gramas nos Pólos Regionais da APTA, Estado de São Paulo em 2002

\begin{tabular}{|c|c|c|c|c|}
\hline Ranking & Pólo Regional & Municípios com flor. & Valor Floricultura & Part. \% \\
\hline $1^{\circ}$ & Sede & 43 & $\mathrm{R} \$ 200.071 .040,97$ & $59,9 \%$ \\
\hline $2^{\circ}$ & Leste Paulista & 21 & $\mathrm{R} \$ 83.736 .687,83$ & $25,1 \%$ \\
\hline $3^{\circ}$ & Sudoeste Paulista & 16 & $\mathrm{R} \$ 14.335 .090,30$ & $4,3 \%$ \\
\hline $4^{\circ}$ & Vale do Ribeira & 14 & $\mathrm{R} \$$ 9.924.158,02 & $3,0 \%$ \\
\hline $5^{\circ}$ & Vale do Paraíba & 15 & $\mathrm{R} \$ 6.533 .899,98$ & $2,0 \%$ \\
\hline $6^{\circ}$ & Centro Sul & 18 & $\mathrm{R} \$ 5.320 .125,54$ & $1,6 \%$ \\
\hline $7^{\circ}$ & Extremo Oeste & 11 & $\mathrm{R} \$ 3.154 .108,85$ & $0,9 \%$ \\
\hline $8^{\circ}$ & Nordeste Paulista & 10 & $\mathrm{R} \$ 2.522 .135,82$ & $0,8 \%$ \\
\hline $9^{\circ}$ & Centro Norte & 14 & $\mathrm{R} \$ 1.941 .286,39$ & $0,6 \%$ \\
\hline $10^{\circ}$ & Centro Oeste & 15 & $\mathrm{R} \$ 1.414 .463,40$ & $0,4 \%$ \\
\hline $11^{\circ}$ & Alta Mogiana & 8 & $\mathrm{R} \$ 1.403 .083,96$ & $0,4 \%$ \\
\hline $12^{\circ}$ & Médio Paranapanema & 8 & $\mathrm{R} \$ 967.444,43$ & $0,3 \%$ \\
\hline $13^{\circ}$ & Alta Sorocabana & 10 & $\mathrm{R} \$ 905.491,36$ & $0,3 \%$ \\
\hline $14^{\circ}$ & Centro Leste & 6 & $\mathrm{R} \$ 630.806,48$ & $0,2 \%$ \\
\hline $15^{\circ}$ & Alta Paulista & 12 & $\mathrm{R} \$ 507.610,64$ & $0,2 \%$ \\
\hline $16^{\circ}$ & Noroeste Paulista & 10 & $\mathrm{R} \$ 419.773,93$ & $0,1 \%$ \\
\hline & Total & 231 & $\begin{array}{l}\text { \$ 333.787.207,89 } \\
\end{array}$ & $100,0 \%$ \\
\hline
\end{tabular}

Fonte: Elaborada pelos autores a partir da TABULAÇÃO (2001) citado por KIYUNA et al. (2003) 
A produção de flores e plantas ornamentais em recipientes (vasos e sacos) de diversos tamanhos e cultivados em substrato adequado para o seu desenvolvimento é uma tendência mundial, devido à grande preocupação com a preservação dos recursos naturais. As inovações permanentes de produtos e processos devem ser constantes e uma obrigação de todos os produtores. Entretanto, esse processo está ocorrendo lentamente na região do Vale do Ribeira, com a apresentação de produtos fora dos padrões do mercado cada vez mais exigente em qualidade.

Para a melhoria da qualidade das flores e plantas ornamentais na região do Vale do Ribeira é necessário investimento em cursos e capacitação de técnicos e produtores, desde o planejamento da produção até a comercialização, principalmente no sentido de promover o associativismo, além de financiamentos mais adequados aos produtores e linhas de fomento para as pesquisas.

\section{REFERÊNCIAS}

JUNQUEIRA, H.; PEETZ, M.S. Exportações de flores e plantas próximas dos US\$ 30 milhões: um novo recorde para o Brasil. Hortíca Consultoria e treinamento. Disponível em www.hortica.com.br/publica.php. Acesso em: 20 maio 2007.

KIYUNA, I.; ASSUMPÇÃO, R.; OTANI M.N.; CASER, D.V.; COELHO, P.J.; ÂNGELO, J.A.; MORALES M.C. Valor da Produção de Flores e Plantas Ornamentais nas Áreas de Abrangência dos Pólos Regionais da APTA, 2002. In: Anais do XLI Congresso Brasileiro da SOBER, 2003, Juiz de Fora/MG.

KIYUNA, I. et al. Estimativa do valor do mercado de flores e plantas ornamentais do estado de São Paulo, 2001. Informações Econômicas, São Paulo, v. 32, n. 5, p. 7-22, 2002.

INFORMATIVO IBRAFLOR. Atibaia, v. 7, n. 23, p. 3-4, 2001.

Tabela 2. Valor da produção agropecuária e estimativa do valor da produção de flores, plantas ornamentais e gramas nos Pólos Regionais da APTA, Estado de São Paulo, 2001

\begin{tabular}{|c|c|c|c|c|}
\hline Rank. & Pólo Regional & Floricultura & Agropecuária & Part. Flor. \\
\hline $1^{\circ}$ & Sede & $R \$ 143.855 .666,57$ & $\mathrm{R} \$ 799.743 .946,97$ & $18,0 \%$ \\
\hline $2^{\circ}$ & Leste Paulista & $\mathrm{R} \$ 60.946 .537,48$ & $\mathrm{R} \$ 812.242 .481,53$ & $7,5 \%$ \\
\hline $3^{\circ}$ & Vale do Ribeira & $R \$ 7.276 .429,54$ & $\mathrm{R} \$ 262.290 .176,15$ & $2,8 \%$ \\
\hline $4^{\circ}$ & Vale do Paraíba & $\mathrm{R} \$ 4.790 .679,74$ & $\mathrm{R} \$ 216.646 .161,62$ & $2,2 \%$ \\
\hline $5^{\circ}$ & Sudoeste Paulista & $R \$ 10.510 .541,47$ & $R \$ 1.059 .097 .090,76$ & $1,0 \%$ \\
\hline $6^{\circ}$ & Centro Sul & $R \$ 3.900 .735,81$ & $\mathrm{R} \$ 1.491 .254 .585,24$ & $0,3 \%$ \\
\hline $7^{\circ}$ & Extremo Oeste & $R \$ 2.312 .604,33$ & $\mathrm{R} \$ 940.198 .192,97$ & $0,2 \%$ \\
\hline $8^{\circ}$ & Nordeste Paulista & $R \$ 1.849 .239,35$ & $R \$ 1.299 .371 .834,51$ & $0,1 \%$ \\
\hline $9^{\circ}$ & Alta Sorocabana & $R \$ 663.909,63$ & $\mathrm{R} \$ 698.837 .424,88$ & $0,1 \%$ \\
\hline $10^{\circ}$ & Centro Norte & $R \$ 1.423 .358,40$ & $\mathrm{R} \$ 1.778 .734 .688,85$ & $0,1 \%$ \\
\hline $11^{\circ}$ & Centro Oeste & $R \$ 1.037 .089,82$ & $\mathrm{R} \$ 1.512 .931 .287,15$ & $0,1 \%$ \\
\hline $12^{\circ}$ & Alta Paulista & $R \$ 372.182,01$ & $\mathrm{R} \$ 570.743 .839,96$ & $0,1 \%$ \\
\hline $13^{\circ}$ & Alta Mogiana & $R \$ 1.028 .746,37$ & $R \$ 1.772 .047 .313,88$ & $0,1 \%$ \\
\hline $14^{\circ}$ & Médio Paranapanema & $\mathrm{R} \$ 709.333,85$ & $\mathrm{R} \$ 1.251 .519 .342,17$ & $0,1 \%$ \\
\hline $15^{\circ}$ & Noroeste Paulista & $\mathrm{R} \$ 307.779,80$ & $R \$ 1.176 .455 .916,77$ & $0,0 \%$ \\
\hline $16^{\circ}$ & Centro Leste & $R \$ 462.509,65$ & $R \$ 1.795 .563 .015,59$ & $0,0 \%$ \\
\hline \multicolumn{2}{|c|}{ Estado } & $\mathrm{R} \$ 241.447 .343,83$ & $\mathrm{R} \$ 17.437 .677 .299,00$ & $1,4 \%$ \\
\hline
\end{tabular}

Fonte: Elaborada pelos autores a partir da TABULAÇÃO (2001) e OTANI; CASER; COELHO (2003) citado por KIYUNA et al. (2003) 